ESCRITAS Vol. 9 n. 1 (2017) ISSN 2238-7188 p. 243-267

\title{
OBRIGATORIEDADE E RESISTÊNCIA: PODER PÚBLICO E VONTADE POPULAR EM COMBATE NO CAMPO DA EDUCAÇÃO ESCOLARIZADA ${ }^{1}$
}

\section{OBLIGATORINESS AND RESISTANCE: PUBLIC POWER AND POPULAR WILL IN COMBAT ON THE FIELD OF SCHOOL EDUCATION}

Wesley Silva ${ }^{2}$

\begin{abstract}
RESUMO: Ao se passarem mais de 30 anos de institucionalização da República apesar de se manter o discurso da educação como condição a consolidação do Brasil como nação - na década de 1920 ainda persistia a dificuldade em se fazer com que a população pobre se apropriasse da escola e da instrução. Entre outros cenários, percebese a instalação de um conflito social tendo, de um lado, o poder público e a escola e, de outro, as famílias e as crianças dessas camadas populares. O desafio persistente é fazer com que suas crianças frequentassem a escola construída pelo Estado, no afã de solucionar o problema do analfabetismo, da pobreza, da criminalidade etc. Todavia a população tenderá a resistir à ingerência do Estado nas famílias, bem como resistir a ideia da escolarização compulsória. O objetivo desse trabalho é analisar aspectos desse conflito a partir da realidade verificada no Estado de Minas Gerais, com atenção especial dada à Capital, Belo Horizonte, no contexto em questão.
\end{abstract}

PALAVRAS-CHAVE: escolarização obrigatória, história da legislação escolar, relação família-escola.

ABSTRACT: After more than 30 years of institutionalization of the Republic although the discourse of education was maintained as a condition for the consolidation of Brazil as a nation - in the 1920s still the difficulty persisted in getting the poor to take over school and of education. Among other scenarios, one can see the installation of a social conflict, on the one hand, the public power and the school, and on the other, the families and children of these popular strata. The persistent challenge is to get their children to go to the state-built school in an attempt to solve the problem of illiteracy, poverty, crime, and so on. However, the population will tend to resist the interference of the State in families, as well as resist the idea of compulsory schooling. The objective of this work is to analyze aspects of this conflict based on the reality verified in the State of Minas Gerais, with special attention given to the Capital, Belo Horizonte, in the context in question.

\footnotetext{
${ }^{1}$ Esse texto é um fragmento do Capítulo II da tese de doutoramento intitulada "Por uma história

${ }^{2}$ Wesley Silva é Doutor em Educação pela Faculdade de Educação da Universidade de São Paulo FEUSP. É professor da Universidade Federal de Alfenas - UNIFAL-MG.
} 
KEYWORDS: Compulsory schooling, history of school legislation, family-school relationship.

\section{INTRODUÇÃO}

Ao se passarem pouco mais de 30 anos de institucionalização da República apesar de se manter o discurso da educação como condição sine qua non para progresso e consolidação do Brasil como nação -, na década de 1920 ainda persistia a dificuldade em se fazer com que a população pobre se apropriasse da escola e da instrução na forma como estas eram representadas pelas classes dirigentes. De outro lado, a própria classe dirigente busca adequar a educação por ela pretendida às novas realidades que se apresentaram com o passar dos anos.

Os anos da década de 1920 serão singulares no processo de efetivação - ou pelo menos na tentativa da efetivação - da escolarização das massas. As populações urbanas no país cresceram e os grandes centros receberam um efetivo maior de pessoas vindas do interior e da zona rural. Em Belo Horizonte, que se aproximava dos 30 anos de fundação, a população havia se multiplicado significativamente (PÁDUA \& MONTE-MÓR, 2004). Ao final dos anos de 1920, início da década de 1930, a crise econômica pela qual passa o país ajudou a desenhar um quadro populacional urbano diferenciado. A crise que atingiu o setor cafeeiro, instalado no interior do Estado, movimentou a população de trabalhadores que tendeu a se dirigir para os centros urbanos. Esse êxodo de trabalhadores rurais irá inchar a população belo-horizontina e chegará a representar, em 1940, 78\% da população urbana (FARIA, 1987, p. 201).

Preocupados com os problemas advindos dessa nova configuração sócioespacial na cidade, segmentos instalados nas instâncias de poder procurarão encontrar explicações e soluções plausíveis para a situação de exclusão em que essa significativa (mas ao mesmo tempo tratada como se insignificante) parcela da população da capital sobrevivia. Um dos argumentos era o de responsabilizar os pobres pelo seu próprio infortúnio ao invés de estabelecer ações públicas de inclusão ou políticas de moradia, emprego e renda. A existência dessa parcela da população vivendo das provisoriedades fará persistir um conflito social tendo, de um lado, o poder público e a escola e, de outro, as famílias e as crianças dessas camadas populares (VEIGA \& FARIA FILHO, 1997). O desafio persistente é fazer com que suas crianças frequentassem a escola construída pelo Estado. 


\title{
A produção da legislação da obrigatoriedade da escolarização
}

\author{
Alinhando-se ao poder público e às classes dirigentes, Ernesto Júnior \\ proclamava a indiferença dos pais na educação dos filhos das classes populares e \\ denunciava que:
}

(...) a meritória campanha de desanalphabetização do paiz, tarefa grandiosa de cunho caritativo e patriótico, há, sempre, defrontado, contrapondo-se valentemente a sua acção, um óbice grandíssimo na criminosa indifferença, no revoltante descaso dos paes pela cultura dos filhos. ${ }^{3}$

O governo mineiro empreendeu, a partir da década de 1920, uma grande cruzada em prol da escolarização de massas promulgando uma série de Regulamentos e Leis visando organizar e/ ou reorganizar o ensino primário no Estado ${ }^{4}$. Essas ações têm como marco a Lei 800 de 27 de setembro de 1920, objetivando reorganizar o ensino primário do Estado. Nesta Lei ficou instituída a obrigatoriedade da matrícula e frequência às aulas de todas as crianças entre 7 anos completos e 14 anos de idade, conforme o que está determinado pelos artigos 31 e 32 :

\begin{abstract}
Art. 31. O professor inscreverá no livro da matrícula todos os menores de 7 annos completos a 14, não possuidores de certificado de approvação no curso primário, promoverá seu comparecimento e freqüência à escola e explicará aos responsáveis por elles as penas em que incorrem pela sua desídia ou contumácia em transgredir a obrigação de educal-os.

Art. 32. Na última quinzena de férias o professor entregará pessoalmente a cada responsável pela educação do menor em edade escolar, uma notificação escripta contendo o nome do menor a designação da escola que é obrigado a freqüentar, o dia do início das aulas e seu horário, e a transcripção das disposições legais sobre a obrigatoriedade do ensino. ${ }^{5}$
\end{abstract}

3

${ }^{4}$ Ernesto Júnior, Bento. Infreqüência nas escolas. In: Revista do Ensino. Orgam Official da Directoria da Instrução. Anno I, n , março de 1925. Bello Horizonte: Imprensa Official do Estado de Minas, 1925, p. 15. A Revista do Ensino é um periódico que começou a circular em Minas Gerais em 1892, mas que teve circulação interrompida logo depois. Em 1925 ela voltou a circular, trazendo conteúdos relativos ao debate educacional e afins. Aqui esse periódico é tratado como fonte histórica e não como referência bibliográfica.

5 Anteriormente, o poder público já havia tentado instituir a obrigatoriedade do ensino em Minas Gerais através de Leis e Regulamentos, a exemplo do que vinha ocorrendo em todo o país. Entre outras iniciativas podemos citar o Relatório do Presidente da Província mineira Antonio Paulino Limpo de 
A Lei, como se vê acima, responsabilizava os professores por uma espécie de recenseamento das crianças em idade escolar. Também se tornou atribuição dos professores a notificação aos pais quando ocorresse a matrícula ex-oficio, ou seja, a partir da iniciativa do poder público, sem a anuência da família. Os professores deveriam esclarecer sobre a obrigatoriedade da frequência às aulas e as sanções aplicáveis aos pais que não cumprissem com o que fora determinado pelo artigo 33, conforme se vê abaixo:

Art. 33. O pae, tutor ou qualquer pessoa que tenha na sua guarda, emprego ou companhia menores de um e outro sexo entre 7 e 14 annos é obrigado a fazelo frequentar a escola, se residir à distancia inferior a três quilômetros della. $\S 1^{\circ}$. Ao infractor será aplicada a multa de $10 \$$, destinada à caixa escolar da escola a cuja circumscripção pertença o menor e cobrável por simples intimação escripta da autoridade escolar, e na falta prisão por três dias. ${ }^{6}$

As determinações da Lei demonstram que o pouco êxito na tarefa de matrícula e frequência à escola levou o Estado a instituir normas mais radicais. As autoridades se mostraram determinadas a fazer cumprir a escolarização nem que para isso fosse necessário ameaçar com medidas extremas que poderiam chegar à prisão dos pais ou responsáveis pela criança em idade escolar. Entretanto, os mecanismos reais para o cumprimento destas determinações não ficam explícitos e não se sabe em que medida a autonomia legada à autoridade escolar lhe conferiria o poder para fazer cumprir o pagamento de multas e mesmo a prisão de pais omissos ou resistentes à ideia da escolarização compulsória. Esta postura, entretanto, despertou resistências e oposição por parte de alguns que a entenderam como extremada. $\mathrm{O}$ entendimento era que as multas e prisões, considerando que as crianças pobres eram as mais ausentes, iriam atingir justamente essa parcela da população já duramente afetada pela escassez e pela carência ${ }^{7}$.

Sucedendo a Lei 800 de 1921, o Decreto 6.655 de 19 de agosto de 1924 aprovou novo Regulamento para o Ensino Primário no Estado de Minas. Este regulamento é bem mais completo e detalhado do que a Lei 800 e traz em seus 566(!)

Abreu, de 1833, a Lei n 41 de 3 de agosto de 1892; a Reforma do Ensino efetuada pelo governador João Pinheiro em 1906, através da Lei 439 de 28 de setembro, entre outras. Ver: SILVA, W: 2007. Capítulo II.

${ }^{6}$ Lei $n^{\circ} .800$ de 27 de setembro de 1920. Estado de Minas Gerais, Coleção das Leis e Decretos. Belo Horizonte: Imprensa Oficial, 1928. Volume 1, 2 e 3. p. 70-80. (p. 74)

${ }^{7}$ Idem, ibidem. 
artigos diversas disposições sobre o funcionamento da escola no Estado ${ }^{8}$. Em seu artigo 228, já prescrevia diretrizes no sentido de tolher a atitude de pais e mães que hora omitiam hora impediam a frequência dos filhos à escola. A preocupação com a escolarização das massas no Estado mineiro, principalmente na jovem capital, é reflexo do que se observa em todo o Brasil, sobretudo após a proclamação da República em 1889. Mário Brant, em artigo alusivo ao lançamento da Revista do Ensino, afirmou que:

Das questões econômica, sanitária e outras que tanto preocupam aos pensadores e dirigentes do Brasil, nenhuma sobreleva a do ensino público. A educação popular é a base de todo avanço material e moral. Um povo ignaro não pode progredir; há de marchar a passo, creando pouco e explorado no seu trabalho e na as produção pelos povos mais esclarecidos. ${ }^{9}$

Por sua vez, Alceu Novaes reproduziu uma reflexão que fundamenta bem o debate que aqui proponho. O texto diz que "todos os regulamentos do mundo não bastariam para fazer de um analphabeto um civilizado" "10. VAGO (1999) destaca a resistência das famílias bem como aponta causas possíveis e explicações para o fato:

\begin{abstract}
Merece destaque a resistência à escola, à sua afirmação como único lugar de acesso ao conhecimento, por parte da população mais pobre, seu alvo central. Ora, se muitos pais não estavam enviando seus filhos à escola, é porque não estavam convencidos da necessidade dela ou, mais especificamente, da necessidade dos conhecimentos que ela veiculava [em relação aos] afazeres mais imediatos das famílias. (p. 68).
\end{abstract}

Apesar de todo o esforço governamental, observa-se, no cenário educacional em Belo Horizonte e outras cidades do Estado de Minas Gerais, a ocorrência de diversos casos nos quais os pais, tutores e responsáveis não matriculavam seus filhos e, quando matriculavam, não garantiam a frequência destes à escola. Além dos textos de Mário Brant e Alceu Novaes citados acima, a Revista do Ensino publicou, a partir do ano de 1925, vários outros artigos e editoriais trazendo apreciações sobre o problema da

\footnotetext{
${ }^{8}$ Essa postura de resistência com relação às multas e a consideração de que elas só penalizariam ainda mais aos pobres já havia sido argumento do Presidente da Província mineira em 1873. Em Relatório enviado à Assembleia Legislativa naquele ano José de Oliveira Lisboa argumentou que os mineiros eram cuidadosos na instrução e na educação dos filhos e que "só impossibilidade absoluta deixavam de mandálos à escola". Para ele, portanto, "a pena de multa, além de injusta, seria ilusória, pois que para torná-la efetiva seria preciso arrancá-la à pobreza, pelo executivo, seus últimos recursos". Apud GONÇALVES \& FARIA FILHO (2004, p. 171-172).

9 Além de ratificar a obrigatoriedade de matrícula e frequência escolar destaco a instituição da Revista do Ensino, através do artigo 479 deste Regulamento, como instrumento de orientação, estímulo e informação aos funcionários do ensino e demais pessoas interessados em assuntos da educação.

${ }^{10}$ Brant, Mário. Uma palavra aos professores. In: Revista do Ensino. Ano I, noo. 1, Março de 1925.
} 
infrequência escolar na capital e outras cidades do Estado de Minas Gerais, pautando-se, sobretudo, no que prescrevia o Regulamento do Ensino primário, promulgado em 1924 pelo Decreto 6.655. São quatro os casos que gostaria de aqui analisar. Os três primeiros reproduziam resposta enviada pela Secretaria do Interior à Senhora Luiza de Siqueira Pinto, professora de Rio Manso, distrito de Diamantina, Minas Gerais.

Três alunos haviam sido matriculados na escola da mestra por meio exoficio. Ao tomarem conhecimento do expediente, os pais, supostamente respaldados pelo artigo 228 do Regulamento do Ensino, alegam diferentes motivos para o não envio dos filhos à escola. Antonio Luiz da Silveira declarou que seu filho era quem tomava conta da casa e, por isso, não podia frequentar a escola, muito embora fosse este desejo do próprio pai. Theophilo Gabriel justificou ser indigente sendo, além disso, um idoso de 80 anos e não possuir recursos para manter o filho na escola. Por último, o Sr. Antonio Balduíno Antunes usou também a pobreza como justificativa para não enviar seu filho à escola argumentando ainda já ter outra criança matriculada. Sendo assim, não possuiria recursos para enviar um segundo filho aos estudos. Sua argumentação deixa transparecer que, o fato de já possuir uma criança frequentando a escola, pode transparecer que, numa família pobre e numerosa, um filho escolarizado já seria suficiente como instrumento de difusão e facilitação do uso da cultura escrita.

De posse das respostas obtidas aos pais, a referida professora enviou então à Secretaria as três declarações emitidas. Em resposta, a Secretaria orientou-a no seguinte sentido:

O $\S 2^{\circ}$ do art. 228 do Reg. citado isenta o notificado de qualquer responsabilidade pela falta da matrícula, si provar, por meios idôneos, qualquer das isenções do art. 228. Entre estas está incluída a pobreza dos paes dos menores, circumstância que invocam dois dos notificados para se isentarem da responsabilidade, as isenções invocadas de pobreza constam do Regulamento e são atendíveis. ${ }^{11}$

Entretanto, a Secretaria alertou para o conteúdo do $\S 1^{\circ}$ do artigo 24 do mesmo Regulamento que determinava: "As isenções devem ser provadas, por meios idôneos, perante os inspectores locaes, dispensada a prova nos casos notórios ${ }^{12}$ ". Sendo assim, a alegação de pobreza deveria ser aferida in loco pelas autoridades escolares, no

\footnotetext{
${ }^{11}$ Novaes, Alceu. Associação das mães. In: Revista do Ensino.Op. cit., p. 31 . O autor do texto cita a frase sem, contudo, explicitar o autor.

${ }^{12}$ Revista do Ensino, $\mathrm{n}^{\circ} 2,1925$, p. 48.
} 
caso mais específico, os Inspetores Escolares locais. No exemplo acima, somente os pais Theophilo Gabriel e Antonio Balduino indicam claramente a indigência como causa para a ausência dos filhos à escola sem, contudo, haverem enviado provas disto. O terceiro caso, o do Sr. Antonio Luiz Silveira não apresenta elementos e sua justificativa é colocada sob suspeita:

\footnotetext{
A alegação feita pelo Sr. Antonio Luiz da Silveira não está no Reg. a menos que a pobreza do notificado seja também motivo que o impede de substituir o filho na direcção de sua casa que não se fica sabendo se é commercial ou de família. Conveniente seria, pois, o notificado esclarecer o assumpto. ${ }^{13}$
}

É também bastante singular o caso de outra menor que foi matriculada exoficio pelo diretor de um grupo escolar do Termo de Bom Despacho da comarca de Pitanguy. O tutor da menor, senhor Augusto Coelho, pessoa conceituada na localidade de acordo com o que informa a fonte, recusou-se a receber a notificação de matrícula de sua tutelada, a menina Maria Anna. A notificação foi a ele enviada pela direção da escola em Bom Despacho depois de efetuar a matrícula da menina Maria Anna. A recusa de Augusto Coelho em receber e assinar a notificação da escola resultou na interferência da Secretaria do Interior, que fora acionada pelo diretor da escola. Foi solicitado um parecer ao consultor Jurídico do Estado, o advogado Tancredo Martins, que desfiou um exaustivo rol de argumentos jurídicos referentes ao fato que deu causa ao problema. Observa-se aqui a forma como as lutas de representações sobre a importância da escola determinam o uso de instrumentos de lutas que respeitam ao lugar onde cada combatente se localiza. Gostaria de começar destacando que ao tutor foi remetida uma notificação de matrícula ex-officio. A notificação de matrícula se constitui, conforme afirma DE CERTEAU (1994), numa estratégia ${ }^{14}$ do poder público de se opor à omissão do mesmo tutor em relação a uma primeira estratégia governamental de obrigar, por meio de lei, que os responsáveis por crianças em idade escolar matriculassem seus filhos. A omissão à obrigatoriedade já foi, em si mesma, uma tática desviacionista para não cumpri-la. Diante de uma notificação, o tutor vale-se de nova tática: recusar-se a assiná-la. A solicitação de um parecer a um Consultor Jurídico é nova tentativa de se obter formas de vencer a resistência do tutor. Revela a posse, por parte do Estado, de um lugar próprio de onde aciona um dispositivo jurídico,

\footnotetext{
13 Idem ibidem.

${ }^{14}$ Idem ibidem.
} 
revelando ter à sua disposição um discurso científico capaz de fundamentar esse seu lugar próprio.

Para o consultor, o fato de não haver o tutor da menor assinado a notificação, não o eximia de ser punido, de acordo com o que determinava o art. 515 do Regulamento. O referido artigo dava margens jurídicas para a responsabilização criminal do tutor, pai ou responsável que se recusasse, por ato ou omissão:

\begin{abstract}
Art. 515. Recusar-se o pae, tutor ou qualquer pessoa que tenha sob sua guarda, a seu serviço ou em sua companhia, menores de um ou outro sexo, em edade escolar, a cumprir as disposições deste regulamento, referentes á obrigatoriedade do ensino primário; não obrigar os menores de quatorze annos e os maiores de dezoito a freqüentar escolas nocturnas, onde as houver; consentir que alumnos sob sua responsabilidade faltem á escola, sem causa justificada, por mais de oito dias durante o mez. ${ }^{15}$
\end{abstract}

Martins concluiu" ${ }^{16}$ o seu parecer afirmando que "a notificação visa exactamente avisar os paes e os tutores ou responsáveis pela matrícula 'ex-officio' dos menores a seu cargo e da obrigação que tem de faze-los freqüentar as escolas”. Para o jurista, os pais "não assignando ou recusando-se a assignar os recibos desta notificação não se eximem da punição comminada; ao contrário liminarmente, incidem nas disposições penais do regulamento ${ }^{17,}$.

É matéria do mesmo parecer uma reflexão do Consultor acerca da obrigatoriedade da educação em Minas Gerais. O jurista buscou fundamentar teoricamente a constitucionalidade do ensino primário obrigatório no Estado. Defendendo o ponto de vista da constitucionalidade, Martins estabeleceu uma comparação entre o referido Regulamento de 1924 e o projeto da Comissão de Instrucção Pública da Câmara dos Deputados ${ }^{18}$ relatado em 12 de outubro de 1882 por Ruy Barbosa. E lança mão das palavras do próprio Barbosa para atestar o principio legal da obrigatoriedade da instrução elementar

Obrigar á instrucção elementar é necessidade e justiça. Necessidade; por que a sociedade humana carece imprescindivelmente de que a intelligencia de

\footnotetext{
15 Os conceitos de Estratégias e Táticas são tomados da teorização de Michel De Certeau (1994).

16 Coleção das Leis e Decretos do Estado de Minas Gerais. Regulamento do Ensino Primário. Decreto 6.655 de 19 de agosto de 1924. Bello Horizonte: Imprensa Official, 1924. (p. 341)

17 Limitar-me-ei a transcrever somente os fragmentos que me parecem ser mais relevantes para o tema abordado.

18 Martins, Tancredo. Obrigatoriedade do ensino em Minas Gerais. Parecer do Sr. Consultor Jurídico do Estado. In: Revista do Ensino, n ${ }^{\circ}$, 1925. p. 75-79. (p. 76).
} 
seus membros preencha ao menos as suas funcções rudimentares, as quais sem certas bases de instrucção não pódem atingir o estado normal. Justiça; porque a paternidade não póde justificar a sua soberania, até ao ponto de condemnar a prole indefesa ao estado mentalmente embryonário da ignorância absoluta. ${ }^{19}$

Sobre a comparação que faz do projeto de Barbosa e o Regulamento de Minas Gerais de 1924, Martins conclui que:

O Reg. do ensino mineiro, de modo algum, contravém as disposições do projecto, ou da Doutrina Constitucional do Parecer do eminente brasileiro. É menos severo, ao contrário, o Reg. do Estado; é mais liberal; mais brandas e mais suaveis são as suas penas que commina aos infractores de seu texto e de suas disposições. Plasmado no modelo do Projecto do Grande Mestre não há quem possa atirar-lhe a pecha de inconstitucionalidade, de coercitivo, de garroteador da liberdade, de tutor tirânico do direito do pae á livre escolha do mestre, da escola e da qualidade do ensino para o filho. ${ }^{20}$

Note-se bem que, apesar de considerar um "direito" do pai a escolha do mestre, da escola e mesmo a qualidade do ensino, o parecerista atesta a condição ambígua desta liberdade que tinha, como outra face, a obrigatoriedade do pai em escolarizar os filhos. Quem educa, onde educa e em que nível de qualidade é uma escolha pautada no direito, desde que exercida a obrigação de escolher. Isto sem que, no exercício de seu direito, sob qualquer hipótese, o responsável se exima ou omita do dever de escolarizar seu(s) filho(s) ou tutelado(s).

Pelos motivos acima expostos, o Consultor Jurídico do Estado decidiu pela aplicação das disposições penais do Regulamento do Ensino contra o senhor Augusto Coelho. De acordo com o que foi publicado no Jornal Minas Gerais, de 10 de maio de 1925, o Consultor opinou pela destituição da tutoria de Coelho "por não cuidar o mesmo da instrucção da referida menor”. Como desfecho do caso, da parte da Diretoria de Instrução emitiu-se a seguinte determinação ao Procurador Geral do Estado de Minas Gerais:

${ }^{19}$ Mister se faz lembrar que, apesar da existência dessa Comissão de Instrucção Pública da Câmara dos Deputados, em 1882, somente em 1890 foi criado o Ministério da Instrucção Pública, Correios e Telégrafos, fruto das reformas encetadas após a Proclamação da República. Ele teve, todavia, existência efêmera, sendo extinto em 1891. Anteriormente, do ponto de vista da organização administrativa, o Ministério do Império era o órgão responsável pela administração do ensino primário e secundário na corte e pelo ensino superior em todo país. Somente em 1930 criou-se o Ministério dos Negócios da Educação e Saúde Pública.

${ }^{20}$ Transcrição de um fragmento do Parecer de Ruy Barbosa sobre a constitucionalidade da Instrução elementar obrigatória no Brasil de 1882. Citado por Tancredo Martins. Revista do Ensino, no. 3. Op. Cit., p. 77. 
(...) peço-vos determineis ao promotor de justiça da comarca de Pitanguy, a que pertence o termo de Bom Despacho, as providências que julgardes necessárias, afim de que não fique burlada a obrigatoriedade do ensino de que trata o novo Regulamento da Instrução. ${ }^{21}$

Como se não bastasse pelejar contra os que podiam ser considerados responsáveis, em outros episódios eram aqueles que, por serem em certo nível inimputáveis - e por isso mesmo tutelados - é que se rebelavam contra as estratégias de conformação. Se nos casos anteriormente citados o que ficou explícito são a responsabilidade e a iniciativa dos pais e tutores, por ação ou omissão, ocorriam também aqueles nos quais se percebia a manifesta resistência dos próprios menores em frequentarem a escola. Não seria errôneo imaginar que, para muitos deles, era mais atraente e prazeroso vaguear e brincar pelas ruas em meio aos palacetes e bairros chiques da cidade do que se permitir enclausurar nos pórticos dos grupos escolares. Em relatório de 13 de dezembro de 1917, o Diretor de um grupo escolar da Capital denunciava o hábito de muitos menores que, tendo saído de casa a pretexto de dirigirem-se à escola, ficavam a vagar pelas ruas. Voltavam depois para casa "às horas habituaes e que durante essas horas [ficavam] pelas ruas em completa vadiação ${ }^{22}$ ”. Os pais, em face do baixo aproveitamento dos filhos, ignorando a burla cometida por estes, retiravam-nos da escola sem buscar saber as causas do baixo aproveitamento. Não se pode negar também a situação de muitos outros que, por já haverem entrado no mundo do trabalho, não podiam ou não queriam conciliá-lo à vida escolar.

Apesar de determinar que a responsabilidade pela matrícula e frequência das crianças à escola era dos pais, tutores e responsáveis, a autoridade escolar sabia que não bastariam as ameaças da lei para garantir a frequência. Por isso mesmo buscava garantir a presença dos alunos através de dispositivos repressivos, como a apreensão de crianças em idade escolar nas ruas, através da ação das forças policiais. No Regulamento de 1924, o Artigo 30 determinava que:

Art. 30: Serão detidos pela polícia, e conduzidos à presença da autoridade escolar, os menores de sette á quatorze annos que forem encontrados a vagar pelas ruas e estradas durante as horas de escola, sem motivo justificado.

Parágrafo único. Na capital, será incumbida desta vigilância a Guarda Civil. ${ }^{23}$

${ }^{21}$ Revista do Ensino, n'. 3. Op. Cit. , p. 78.

22 Obrigatoriedade do ensino. Diretoria de Instrucção. In: Revista do Ensino, n ${ }^{\circ}$. Op. cit., p. 110.

${ }^{23}$ Secretaria do Interior. Relatórios dos Diretores de Grupos Escolares. 1918. 
O que parece estar implícito é que, mesmo quando há o empenho dos pais em matricular os filhos, mesmo que a escola utilize o artifício da matrícula compulsória, necessariamente não quer dizer que se poderá contar com a passividade da criança em se dirigir amavelmente à sala de aula. As cidades e as ruas viviam repletas de apelações e atrativos que se mostravam bem mais interessantes do que as tarefas escolares. Vagar pelas ruas, praticar o recém trazido foot-ball ou qualquer que fosse o passatempo, poderia ser bem mais divertido que suportar as muitas horas sentado em sala de aula (FARIA FILHO, 1996; e VAGO 1999). Assim sendo, a ação da segurança pública se junta à legislação como estratégia: ia-se para a escola nem que fosse conduzido pela polícia.

O Regulamento 7.790-A de 15 de outubro de 1927 reforçará o caráter jurídico da obrigatoriedade continuando, todavia, a se debater com pais e filhos que demonstravam, com suas ações ou omissões, persistência e resistência à ideia da escolarização. A pouca frequência, denunciada pelas fontes citadas acima, deixam ver que pais e crianças se mostravam refratários ou indiferentes à escola mesmo que o Regulamento reforçasse a compulsoriedade da frequência e prescrevesse penalidades aplicáveis em seu artigo 29:

\footnotetext{
Art. 29. (...) a falta imotivada, de freqüência escolar por três dias consecutivos será communicada ao pai ou responsável, para que as justifique. Si não for satisfactoriamente explicada, o responsável pela creança incorrerá nas penas do artigo anterior. ${ }^{24}$
}

Perceba-se, primeiramente, que o número de faltas consecutivas permitidas fica aqui estabelecido em apenas três, o suficiente para que o pai ou responsável fosse inquirido pela autoridade escolar. Esse prazo foi diminuído em relação ao Decreto 6655 de 1924, já que no artigo 515 deste a tolerância era de 8 faltas em um mesmo mês letivo. O texto evoca ainda o artigo de número 28 do mesmo Regulamento que determinava que pais ou responsáveis devessem se reportar à autoridade competente quando inquiridos acerca da instrução primária a ser obrigatoriamente garantida a seus filhos e tutelados. Nos parágrafos $1^{\circ}$ e $2^{\circ}$ do artigo 28 ficavam instituídas as penalidades para aqueles que não atendessem ao que nele está disposto, conforme se segue:

\footnotetext{
${ }^{24}$ Regulamento do Ensino, 1924. Op. Cit., p. 219. O Regulamento de 1927 trás a mesma determinação no artigo 32. Op. Cit., p. 1147 e 1148.
} 
$\S 1 .^{\circ}$ Os que não atenderem ao disposto nesse artigo serão passiveis da pena de multa de cinco mil a dez mil réis, imposta pela auctoridade escolar competente, e pagável no prazo de 8 dias.

$\S 2 .^{\circ}$. Em caso de não pagamento ou de reinscidência, na infracção, a multa será em dobro. O não pagamento desta última importará em prisão correcional, para o que a auctoridade escolar requisitará á auctoridade policial as providencias convenientes. ${ }^{25}$

O que foi exposto acima, principalmente no $\S 2^{\circ}$, traz um dilema com o qual as autoridades deverão conviver naquele período: a escolarização das camadas pobres da sociedade aos poucos vai transcendendo do campo de competência que é dos setores públicos interessados pela educação em específico, para outro campo que é do setor público responsável pelo provimento da segurança, manutenção da ordem e de auxílio ao setor jurídico no cumprimento da ordem estabelecida. O ideário republicano de onde se tomou, primariamente, a noção de que a educação era fator de ordenamento político e cultural agora orienta para a necessidade da ordenação pública como elemento necessário à plena execução da tarefa de escolarização. Cria-se assim uma representação de que a resistência à escolarização pode ser entendida, para além de uma questão de nacionalidade, cultura, progresso e economia, como uma questão de segurança pública $^{26}$.

Mas conforme propomos acima, não é somente da parte de pais e responsáveis que se manifesta a resistência à ideia de escolarização compulsória. Das crianças também virão atitudes dignas de serem apreciadas. Já relatei anteriormente a indignação de um diretor diante da atitude de alunos que, tendo saído de casa supostamente em direção à escola, ficavam a vagar pelas ruas por todo o período que deveriam estar em sala de aula numa manifestação de resistência passiva, ou seja, aquela através da qual se resiste sem travar confronto direto. Como se não bastasse esse tipo de burla, a escola tinha que enfrentar ainda os casos nos quais a própria criança tomava iniciativa de se opor abertamente à ideia de escolarização. Reproduzo, como exemplo, um caso, para mim inusitado, que retrata a postura de um aluno frente à iniciativa governamental da educação escolar obrigatória.

Em 14 de março de 1930, a senhora Amélia Franco, professora do Grupo Escolar Conselheiro Affonso Pena da cidade de São Gothardo, interior de Minas Gerais,

${ }^{25}$ Decreto no 7.970 de 15 de outubro de 1927. Regulamento do Ensino Primário. Op. cit. p. 1147.

${ }^{26}$ Idem, p. 1146 e 1147. 
envia uma notificação ao pai de um aluno questionando-o quanto ao acúmulo de faltas de seu filho às aulas. Ao Sr. Arthur Antonio Amaro é enviada a seguinte comunicação:

\begin{abstract}
Ao Snr. Arthur Antonio Amaro:
Communico-vos que seu filho Aristides Antonio Amaro já faltou às aulas por 7 dias seguidos. E como o artigo 29 do Reg. estatue multas aos responsáveis por alumnos matriculados em qualquer escola ou grupo, peço-vos o obsequio de declarar, no verso desta, o motivo que deu causa áquellas faltas, para o fim de justificação, se for o caso.

Esse aviso deve ser devolvido.

A Professora

Amélia Franco ${ }^{27}$
\end{abstract}

Chamo a atenção para alguns aspectos importantes que devem ser observados atentamente na comunicação acima. Primeiramente, ela está datada de 14 de março de 1930. Três anos após a promulgação do Regulamento de 1927 ainda se enfrentam problemas com a infrequência de alunos matriculados mesmo que muitos deles já houvessem sido matriculados ex-oficio, ou seja, compulsoriamente. No caso acima, as faltas são comunicadas aproximadamente quarenta e cinco dias após o início das aulas, já que o Regulamento determinava o dia $1^{\circ}$ de fevereiro como data para o início do ano letivo. Outras questões são relevantes de serem analisadas a partir deste caso específico. O texto da comunicação determina que o verso do documento deveria ser utilizado para a resposta do responsável pelo menor devendo ela ser devidamente explicitada e devolvida ao remetente. Subentende-se que o pai ou responsável deveria ser pessoa alfabetizada em condições de declarar por escrito tal justificativa. No exemplo aqui relatado, o pai teria atendido a solicitação da autoridade escolar e utilizado o verso do documento para emitir uma resposta que também pode revelar elementos importantes. O senhor Antonio Amaro, pai do faltoso Aristides, teria respondido repleto de autoridade, o que faço questão de por em destaque:

O Aristides não vai não porque elle não foi matriculado e elle não quer ir $^{28}$

A atitude do Sr. Antonio coloca em evidência vários elementos que nos expõem a atmosfera de conflito existente entre a escola e a família considerando para isso a própria opinião da criança em idade de escolarização. Primeiramente, ao afirmar

\footnotetext{
27 Uma discussão mais completa a esse respeito é realizada no Capítulo III da tese de onde se originou esse trabalho: SILVA, 2007: p. 109-167.

${ }^{28}$ Ofício do Grupo Escolar Conselheiro Affonso Penna. 14 de março de 1930. Arquivo Público Mineiro.
} 
que a criança não foi matriculada, o pai nos deixa margem para entender que a criança fora matriculada compulsoriamente, ex-oficio, conforme determina o Regulamento, a despeito da vontade da família. O fato de a escola possuir um cadastro da criança, constando inclusive o nome completo do pai, somado ainda à data de emissão do documento, deixa claro que a criança havia sido oficialmente matriculada dentro dos limites temporais exigidos pelo Regulamento. Expõe ainda a possibilidade de que tais dados tenham sido aferidos mediante o recenseamento escolar. Além disso, ao declarar que a criança já havia faltado a sete dias consecutivos demonstra que Aristides Amaro frequentou a escola por certo período de tempo vindo posteriormente a insurgir-se contra a obrigatoriedade. A resposta da família revela então sua disposição em contestar a autoridade da escola para obrigar seus membros mais novos a frequentarem uma sala de aula. Ao declarar que a criança, além de não matriculada, não quer ir, o pai revela, de um lado, um interesse dúbio pela escola; de outro lado, a resistência da própria criança além da anuência da família para com a vontade do filho. Demonstra igualmente a disposição da família em questionar a autoridade da escola em se valer da matrícula exoficio como estratégia de registro escolar. $\mathrm{O}$ debate aqui assume aqui, de acordo com FARIA FILHO \& VIDAL (2000), a forma de uma "disputa entre o governo da casa e o governo da escola", evidenciando outras dimensões das práticas sociais de escolarização. Fica latente a existência de um conflito que sinaliza a pluralidade de representações acerca de escola, escolarização e vida social, o que inclui modos de organização familiar e parâmetros da relação entre seus membros. É preciso estar atento, igualmente, para o fato de que o repertório utilizado pela autoridade escolar e pela família evidencia uma troca entre ambas, fundada no pressuposto do consumo produtivo e não passivo. Conforme exposto por VIDAL (2004), com base em DE CERTEAU (1994), "as estratégias do poder e as táticas de subversão sinalizam o consumo produtivo dos sujeitos, acionado em situações diversas e em função do repertório de possibilidades de atuação que cada grupo detém”.

A se considerar que, de fato, a resposta tenha sido escrita pelo próprio pai, mãe ou qualquer pessoa autorizada a redigir pela família, manifestando, no entanto, o seu próprio desejo, fica margem para mais uma constatação importante. A literatura histórica sobre a escolarização e a infância nos traz análises que dão conta do grande preconceito das autoridades com relação às famílias pobres no que diz respeito à resistência destas em enviar seus filhos à escola, conforme analisam DEMARTINI 
(2001) e CUNHA (2000). O principal argumento é aquele, em geral, de que pais e mães analfabetos fazem padecer os filhos do mesmo mal que os aflige. São ignorantes e iletrados e por isso não fazem questão da escolarização da prole. Esta representação produz como principal resultado a constatação que a mobilidade geracional em educação é significativamente menor entre filhos de pais com baixa escolaridade que entre filhos de pais com escolaridade mais elevada ${ }^{29}$. Isto corrobora, inclusive, para atestar a transmissão intergeracional da pobreza ${ }^{30}$ cultural, a exemplo do que se observa com a pobreza do capital financeiro ${ }^{31}$.

Marcus Cunha esclarece que, de início, a família da classe trabalhadora não aparece como problema para a escola já que as crianças oriundas desse extrato da sociedade não frequentavam maciçamente a esta instituição social. Após a pretensa democratização da escola, a presença dessas crianças sugere a necessidade de que o poder público passe a se preocupar com suas famílias, de acordo com o que assinala CUNHA:

Dado que a principal meta da escola renovada era a de educar crianças e jovens na direção de um ideal de sociedade, era preciso adequar a esse ideal todos aqueles que constituíssem obstáculo ao desenvolvimento social. Desse modo, lidar com a falta de qualificações da família pobre para educar os próprios filhos significava abordar um assunto que dizia respeito aos destinos da nação (2010, p. 459).

O domínio da palavra escrita e a capacidade de fazer uso social ${ }^{32}$ dela para questionar a autoridade escolar no verso do documento originado na própria escola demonstram que, a despeito de ser ou não alfabetizado, o pai ou responsável do caso acima se achava no direito de escolher enviar ou não seu filho à escola. Considera-se também aqui a vontade da própria criança ao menos pretensamente manifesta na fala do pai. Sua postura deixa antever uma disputa pela autoridade e responsabilidade pelos

${ }^{29}$ Resposta do senhor Aristide Amaro ao Ofício do Grupo Escolar Conselheiro Affonso Penna. 14 de março de 1930. Arquivo Público Mineiro.

30 Aqui, recorro ao Campo da teorização da Economia para efetuar esta afirmação. O conceito básico desta constatação é o de Mobilidade intergeracional de educação. A esse respeito pode-se consultar, entre outros, Ferreira \& Veloso (2003).

31 A respeito do conceito de Transmissão Intergeracional da Pobreza sugere-se consultar: Neves (2003). É possível consultar também: Rocha(2003).

32 Poderíamos considerar a hipótese de que o menor tenha respondido, ele próprio, ao bilhete enviado pela professora. Sem querer aprofundar o mérito da questão, uma análise das formas caligráficas da resposta dada no verso do bilhete nos dá a entender tratar-se da escrita de um adulto, e não de uma criança em fase inicial de alfabetização. Por isso não trabalho com a hipótese de que a resposta tenha sido dada pelo próprio Aristides. 
próprios destinos da família, conforme avaliam NOGUEIRA \& ALMEIDA (2002). É possível considerar também a produção de uma representação acerca do valor da escolarização e da cultura escolar das famílias das classes populares que se choca com a representação oficial e hegemonicamente assumida pelas famílias abastadas (muito embora não totalmente ausente de conflito $^{33}$ ).

Refletindo sobre o papel da família em cooperação com a obra da escola, Faria de Vasconcellos, eminente médico português, declarou que "o estudo scientífíco da creança, a collaboração do médico e do pedagogista, tornar-se-iam estereis quando

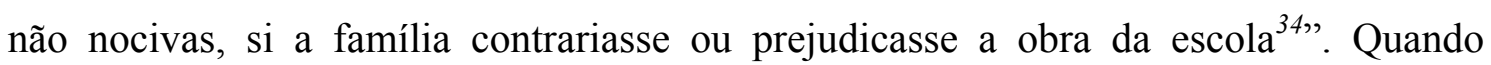
evidencio uma disputa de representações acerca da escolarização e da escola busco assinalar, com base em CHARTIER (1990), que a família pobre pretendia a escolarização, mas em moldes que lhes fossem favoráveis. A organização temporal, na qual a escola se pautava, mostrava-se como um grande empecilho para a frequência das crianças, sobretudo as mais pobres. Essa forma escolar, para nos valermos da expressão de VINCENT (2001), pressupunha um conflito de interesses na utilização do tempo pela família e pela escola. Para VIDAL,

\begin{abstract}
A prioridade à instituição escolar, desejada pelas autoridades educacionais, contrastava com a posição complementar a ela conferida pelas demais instituições sociais, neste caso a família. As penalidades previstas, como multa pecuniária, não eram suficientes para assegurar nem a regularidade da presença nem a pontualidade dos alunos e, seguramente, não estimulavam a permanência nos bancos escolares durante todo o curso primário. Para os pais, as crianças deveriam ir à escola, mas no horário que lhes fosse mais conveniente e de acordo com os projetos familiares concebidos para cada membro (2004, p 11-12).
\end{abstract}

Em face de uma realidade descrita acima, a Diretoria de Instrução apelava pelos meios disponíveis aos professores, diretores e mesmo inspetores de ensino, que envidassem todos os esforços para aumentar a matrícula, a frequência e $o$ comparecimento aos exames:

Aos srs. professores e directores de grupos escolares recommendo o maximo empenho, de or'avante, para que obtenhamos nas escolas maior freqüência, melhor comparecimento aos exames e melhor resultados nestes. No passado

33 Ao destacar a habilidade do pai em questão em fazer uso social da leitura e da escrita, procuro evidenciar uma habilidade que vai além da simples grafia e decodificação de símbolos linguísticos. A esse respeito consultar sobre alfabetização e letramento em Magda Soares (2003).

34 A esse respeito é possível consultar também Nogueira, Romanelli, \& Zago. (Orgs.). (2000). 
anno letivo, salvo magníficas exepções, foi a freqüência bastante frouxa e pequeno o comparecimento aos exames.(...) Faço, pois, um apello a todos os professores e auxiliares de ensino para que envidem todos os seus esforços no sentido de obtermos grande freqüência nas escolas e um ensino cada vez mais satisfactorio. $^{35}$

Considerando que a frequência era baixa, muitos alunos deveriam iniciar, mas não chegavam ao final do ano letivo o que determinava a abstinência aos exames. Em tom de ameaça, a Diretoria de Ensino advertia aos professores: "não serão conservados nos seus cargos os professores em cujas escolas não corresponderem os exames ao que se tem o direito de exigir ${ }^{36, " ~ E s s a ~ m a n i f e s t a c ̧ a ̃ o ~ d o ~ D i r e t o r ~ d e ~ E n s i n o, ~}$ Lucio José dos Santos, deixa claro o grau de responsabilidade atribuído aos professores em face do aparente insucesso da escola obrigatória para as massas e nos permitem ver mais: o fenômeno da repetência, do fracasso escolar e da infrequência são frutos indesejáveis do surgimento dos grupos escolares e da obrigatoriedade da matrícula. Em 1941, a diretora Ignácia Ferreira Guimarães expunha o problema das reprovações:

Muitas reprovações se verificam todos os anos nas escolas de todos os gráos. A percentagem de approvações não tem sido absolutamente satisfactoria. Nas escolas primárias de Minas, por serem mais numerosas que as secundárias, esta irregularidade salienta-se tanto que chamou já a attenção do Governo, tendo este iniciado uma decidida campanha em prol de maior efficiência no ensino. $^{37}$

O que Ignácia Guimarães evidenciava é que, apesar de um número razoável de registros de matrículas ser efetivado pela escola, o aproveitamento final persistiu em baixo percentual. Adentrando a década de 1920, o pequeno número de matrículas, acrescido do problema da evasão e do baixo aproveitamento escolar, será ainda motivo de preocupação, em contraposição à busca pela eficiência do sistema escolar. Os dados produzidos pelo poder público servirão de respaldo às críticas e considerações emitidas pela imprensa acerca da eficiência da escola no Estado.

Uma estatística de 1927 sobre o ensino em Minas Gerais apresenta uma matrícula de 252.208 alunos, para 13.845 de conclusão de curso, ou vale dizer que mais de $70 \%$ dos alunos deixaram a escola antes de terminar o período regulamentar. Ora, a população em idade escolar de 7 a 14 anos era, em 1920. De 1.318.365 indivíduos. Esse número, mesmo desfalcado do

35 Faria de Vasconcellos. Apud Alceu Novaes. Associação das Mães. Revista do Ensino, n ${ }^{\circ}$, 1925, p. 31. Alceu Novaes não explicita a fonte do que foi por ele citado.

${ }^{36}$ Revista do Ensino. no ${ }^{\circ}$ 1, 1925. Op. cit., p. 21.

37 Idem ibidem. 
aumento relativo aos sete anos decorridos até 1927 , cotejado com os 13.845 de conclusão de curso, torna supérfluo qualquer comentário a respeito. ${ }^{38}$

Em virtude desta diminuição evidente, as autoridades tentarão produzir meios, além dos jurídicos e legislativos, para fazer com que os estudantes cursem todo o ensino primário sem desistências e com maior aproveitamento nos exames. Entre as muitas estratégias para garantir a permanência das crianças nas escolas, as autoridades escolares recorrerão ao Regulamento do Ensino e determinarão a criação emergencial das Caixas Escolares. Estas instituições já haviam sido anteriormente previstas, por exemplo, no $\S 1$, artigo $3^{\circ}$ da lei 800 de 27 de setembro de 1920 . Novamente lembradas no Artigo 470 do Decreto 6.655 de 19 de 1924, deveriam desempenhar função primordial visando "facilitar a freqüência dos menores indigentes". As Caixas Escolares deveriam impedir que a pobreza e a necessidade de trabalhar para auxiliar no sustento da família servissem de pretexto à ausência desta parcela de crianças à escola. Os pobres constituíam, segundo exprimiam os discursos oficiais, a classe que mais deixava de cumprir a obrigatoriedade escolar ${ }^{39}$. A maneira concreta de prestar assistência seria através da distribuição de prêmios, fornecimento de merenda, distribuição de roupas e calçados, distribuição de objetos indispensáveis para uso pessoal do aluno pobre e fornecimento de medicamentos etc. ${ }^{40}$ Mais uma vez a Revista do Ensino servia de veículo de informação às professoras chamando-lhes a atenção para:

(...) o dever que lhes cabe de auxiliar as directoras dos grupos no trabalho pelo desenvolvimento das caixas escolares. Instituição de auxílio às creanças pobres dos grupos, visando entre outros fins o de augmentar a freqüência escolar, devem as mesmas caixas merecer todo o interesse das professoras, que farão com todo o cuidado e rigor as listas dos alumnos que estejam em condições de receber aquelle auxílio. ${ }^{41}$

\footnotetext{
${ }^{38}$ Guimarães, Ignacia F. Porque se reprovam tantos alumnos? In: Revista do Ensino. Anno I, n ${ }^{\circ} 2,14$ de abril de 1925. Bello Horizonte: Imprensa Official do Estado de Minas Gerais. Órgam Official da Inspectoria Geral de Instrucção. Ignácia Ferreira Guimarães exerceu, entre outras funções, a direção do $5^{\circ}$ Grupo Henrique Diniz, instalado na Capital mineira em fevereiro de 1914; foi professora da Escola de Aperfeiçoamento, Chefe da Seção de Programas e Atividades Extra-classe do Departamento de Educação do Distrito Federal.

39 Pinto, Yvon de Magalhães. A política educacional brasileira. Jornal Estado de Minas. Belo Horizonte, 14 de novembro de 1933, p. 4.

40 Apesar de assinalar a presença de um contingente de $31 \%$ de crianças consideradas pobres matriculadas na referida instituição, VAGO (1999) propugna por uma disputa de classes em torno da ocupação deste lugar escolar (p. 330-332).

${ }^{41}$ Revista do Ensino. no. 1, 1925, p. 20.
} 
Os recursos para a instalação e manutenção das caixas adviriam de multas cobradas aos pais que descumprissem as determinações do Regulamento, das multas aplicadas a professores por faltas injustificadas ao serviço e também de doações de sócios e contribuintes. Denunciando o estado precário das Caixas Escolares ao mesmo tempo em que criticava a destinação de recursos para fins supérfluos em detrimento dos investimentos na educação pública, o jornal $O$ Debate sugeria que "se reservasse alguma coisa dos banquetes dos políticos para socorrer a infância necessitada." ${ }^{42}$ Julgava-se necessário interferir de forma que a satisfação de uma alimentação mínima pudesse cumprir dois papéis: impedir que a inanição interferisse na frequência e no aprendizado, em função das constantes vertigens e desmaios sofridos pelos alunos em sala e ao mesmo tempo servir de atrativo para que as crianças fossem à escola, nem que o maior interesse estivesse no alimento servido. As dificuldades financeiras das famílias eram manifestas no estado de desnutrição e inanição que certos alunos apresentavam, principalmente em escolas de periferia.

\begin{abstract}
A desnutrição da nossa infância escolar é visível. Quem olha os meninos pobres nas escolas de certos bairros tem a sensação da vida dura e necessitada que passa esse infeliz. Olhos escovados, faces pállidas e magras, membros esqueléticos...Tudo isso é a tragédia muda da indigência, do lar operário, do desemprego, das bocas que pedem pão e recebem uma ração minguada que não satisfaz as exigências orgânicas. ${ }^{43}$
\end{abstract}

Não eram poucos os casos em que, no interior das salas de aulas, alunos se sentiam mal, manifestando tonteiras, vertigens e sofrendo desmaios, motivados aparentemente pela carência de alimentos.

Todo o nosso professorado, e principalmente o dos bairros pobres, conhece bem esses casos de vertigens. Os pobrezinhos, em plena aula, empallidecem mais, oscillam sobre si mesmos e desfallecem sob o olhar da mestra. Há a lufa lufa natural dessas horas. Água. Café, ether, óleo canphorado. Mas as professoras e enfermeiras já sabem qual é o remédio- uma sopinha tônica e reconfortante. É a falta de alimentos que vem a determinar essas vertignes. Falta do que comer em casa, porque o pae ou a mãe não tem com que comprar o necessário. Deiante dessa dolorosa situação seria um crime cruzar os braços. ${ }^{44}$

\footnotetext{
42 Idem, ibidem.

43 A pobreza das Caixas Escolares. Jornal O Debate. Belo Horizonte, 3 de outubro de 1934, p. 1.

44 Para amparar o pobre e melhorar a raça- A obra generosa das cantinas escolares. Correio Mineiro, quinta-feira, 24 de janeiro de 1935.
} 
Numa tentativa de pôr fim a esse problema, em 23 de janeiro de 1935 Mário Campos presidiu a sessão inaugural de instalação da cantina na Escola Infantil Delfim Moreira. Na ocasião, lançou-se oficialmente a Associação das Cantinas Escolares. O Estatuto da Associação foi lido e aprovado por aclamação. Para presidi-la foi eleito o senhor Cândido Naves. A diretoria ficou ainda composta da seguinte maneira: vicepresidente: J.J. Monteiro de Andrade; tesoureiro: Teófilo de Melo Santos; $1^{\mathrm{o}}$ secretário: Dinam Meneses Rodrigues Louzada; $2^{\mathrm{a}}$ secretária: D. Maria Julieta Ramos; conselho fiscal: Eugenio de Souza, Gastão de Matos, Aureliano Tavares. Outra importante figura presente à sessão foi o então Diretor da Inspectoria de Hygiemme Escolar, J. Castilho Junior. Entusiasmado com o empreendimento lançado, Castilho Júnior afirmou que:

\begin{abstract}
A Associação das Cantinas Escolares, composta de pessoas de boa vontade que concorrerão com uma quantia módica, tem por fim: prover a alimentação racional às crianças das escolas primárias, educal-as no que respeita a hygienne alimentar; servir de centro de estudos e observação sobre a alimentação em geral e particularmente nas escolas. Temos grande esperança no sucesso e nos benefícios das cantinas. Já que é tão difícil actuar sobre o que já está feito e formado, eu tenho fé que será mais possível modificar o organismo nacional e melhorar a nossa raça agindo sobre os pequeninos. Temos para com os menores uma dívida immensa a saldar. E é com o saldo dessa dívida que poderemos melhorar o conjunto da collectividade. ${ }^{45}$
\end{abstract}

Se ao longo dos anos de 1920 e 1930, apesar de todos os esforços oficiais e de particulares, a ação das caixas foi muitas vezes incipiente, insuficiente ou mesmo inexistente, na década de 1940 o governo mineiro buscou resolver de vez esse problema determinando a obrigatoriedade dessas instituições em todas as escolas do Estado. Essa atitude mereceu elogios e reconhecimento inclusive de outros Estados e também da Capital Federal. De lá, uma reportagem do jornal $O$ Globo comentou a iniciativa do governo de Minas Gerais em tornar obrigatória a criação das Caixas Escolares em todas as escolas primárias do estado:

(...) a propósito de umas tantas providências de que carecem mais de um sector de nosso ensino, foi lembrado o benefício da instituição das Caixas Escolares, sabido como é que bem pouco vale o maior desvelo das assistências da saúde, a mais pontilhosa vigilância médica, quando os alumnos estão mal alimentados e empalidece de fraqueza á hora da merenda que lhes falta, ou quando se sentem humilhados por falta de material escolar ou o estado deplorável das vestes rotas. ${ }^{46}$

45 Idem ibidem.

${ }^{46}$ Idem ibidem. 
Em face do problema da desnutrição, da inanição e dos desdobramentos indesejáveis deles na frequência e no aprendizado escolar, o jornal carioca ressaltou

(...) o alto valor das Caixas Escolares, digna de todo o estímulo da parte do poder público, porquanto é através dellas que se attendem a feições delicadas do assumpto, quaes as que se prendem ao fornecimento da merenda, das roupas e dos livros, e do mais material da escola aos alumnos pobres. Porque são essas deficiências, compreensíveis como as angústias de tantos orçamentos de famílias menos aquinhoadas do destino, e cujos filhos, por força mesma de tão constrangedoras circunstâncias, ficam tantas vezes privados de freqüentar as escolas, que inspiram o desenvolvimento das Caixas Escolares em apreço, as quais florescem, por via de regara, ao influxo da solidariedade e sympathia dos cidadãos melhores sorteados. ${ }^{47}$

Entendendo a necessidade de que há muito as escolas brasileiras careciam de um instrumento valioso no auxílio à escolarização das crianças pobres, destaca-se o exemplo digno de ser seguido pelos governos estaduais de todo o país.

É esse exemplo que acaba de dar o governo mineiro, graças a um decreto em que o sr. Benedito Valladares imprimiu uma orientação mais definida e fecunda à existência dessas Caixas Escolares, tornando-as obrigatórias em todos os estabelecimentos de ensino primário, e a todas fornecendo recursos certos, além dos que lhes possam ministrar as attitudes da iniciativa privada, sem cujo auxílio a instituição perderia muito da própria expressão que a embeleza e como que a sublima, por fartos que pudessem ser os auxílios da administração. $^{48}$

Conforme se percebe, a partir desta interferência do governo mineiro, ao tornar obrigatória a existência das cantinas e caixas em todas as escolas do Estado, assegurou-se a destinação de recursos públicos para o financiamento da merenda escolar, mas sem que se prescindisse do auxílio de particulares. O que está implícito é que até esse momento a existência das Caixas era facultativa ficando, por isso, condicionada à manutenção advinda de doações privadas e da arrecadação das multas aplicadas a pais e professores, de acordo com o que estabelecia o Regulamento de Ensino $^{49}$. A transformação das Caixas em instituição escolar de existência obrigatória delega ao Estado o dever de destinar recursos públicos a esse fim. Entretanto, os recursos das multas, mas principalmente as doações privadas continuam a ser

\footnotetext{
47 Idem ibidem.

${ }^{48}$ Idem ibidem.

${ }^{49}$ Idem ibidem.
} 
solicitados pelo governo, entendidos como importante parcela financeira da manutenção das Caixas.

Mas, se de um lado os gestores da escola faziam esforços para aumentar e manter a frequência, por vezes encontravam obstáculos dentro da própria escola, naqueles que deveriam servir de auxílio nesta campanha. A Secretaria do Interior em determinado momento, viu-se na obrigação de advertir severamente a alguns diretores e diretoras que, mesmo com toda a campanha pelo aumento da frequência escolar impediam alunos pobres, que não possuía o uniforme escolar, de se matricularem e frequentarem as aulas. Quanto à exigência de uniformes a referida Secretaria advertiu que:

\begin{abstract}
$\mathrm{O}$ uso do uniforme para os alumnos nos grupos escolares do Estado tem a approvação da secretaria do interior. Os directores das casas de ensino e os professores, trabalhando pela adoção delles, fazem, pois, um trabalho elogiável, que a Secretaria com empenho recommenda. Além das vantagens materiais que este costume traz ao ensino, como por exemplo os movimentos colletivos em favor do vestuário para os alumnos, o uniforme faz com que o corpo discente do estabelecimento apresente uma nota egual no vestir, niveladora de todos pelo [sic] simplicidade e beleza no vestir. ${ }^{50}$
\end{abstract}

Todavia reprovava e condenava a atitude dos diretores e professores que, exagerando na exigência do uniforme escolar, impediam a presença de crianças desuniformizadas nas escolas. Destacavam com isto o desserviço que aqueles prestavam ao projeto de escolarização obrigatória das massas.

\begin{abstract}
Alguns professores de grupos escolares têm, entretanto, conforme chegou ao conhecimento da Secretaria, impedido a matrícula a alguns e a têm cassado a outros pelo motivo da falta de uniformes. A Secretaria torna público que não póde tolerar esta medida, porque o ensino é obrigatório em nosso Estado. ${ }^{51}$
\end{abstract}

E concluía demonstrando a forma adequada, do ponto de vista da Secretaria do Interior, como os diretores escolares deveriam agir:

Não é assim que os directores devem agir. O seu trabalho, para a adopção dos uniformes deve revestir-se de um cunho superior, deve ser como que um trabalho de persuasão, que seduza, que seja capaz de abrir ainda mais (e nunca trancar) as portas da escola. ${ }^{52}$

\footnotetext{
${ }^{50}$ Regulamento do Ensino 1924. Op. cit., p. 330-332.

${ }^{51}$ Revista do Ensino, n'. 11, 1926. Op. cit., p. 64.

${ }^{52}$ Idem ibidem.
} 


\section{Considerações finais}

Conforme tentamos demonstrar, o quadro de ausências às matrículas, infrequência e repetência é desenhado numa tela onde se expõem conflitos de interesse entre o poder público, a escola, a família e as crianças. A batalha entre as representações construídas acerca do projeto de escolarização obrigatória se desenrola e cada grupo de interesse utiliza das armas de que dispõe. De seu lugar de poder, a escola e demais instâncias de gerenciamento lançam suas estratégias de controle e subjugação. Nas lacunas quase imperceptíveis das iniciativas oficiais, as táticas de resistência e sublevação vão sendo lançadas como forma de fazer escapar aqueles aos quais se destinam as tentativas de controle e modelização. Em muitos casos, não se exige muito esforço já que a condição socioeconômica dos grupos subordinados torna-se, ela mesma, arma tática usada contra o poder constituído. A pobreza, a falta de trabalho e renda, a distante localização das moradias - condições impostas pela própria configuração socioeconômica e urbana da cidade -, acabam por se tornar em empecilhos na realização plena do projeto de escolarização para as massas.

É preciso, todavia, lançar um olhar crítico e questionador sobre essa representação hegemônica de que as classes pobres não se interessavam pela escolarização. Esta representação se relacionaria a dois importantes fatores. De um lado, em face do relativo fracasso de todos os esforços empreendidos pelos governantes para se escolarizar as massas, buscava-se produzir justificativas plausíveis para os baixos índices de escolarização da população num momento em que se buscava afirmava-se, exatamente, a importância da educação e da escola. De outro lado, esta representação desqualificadora das classes populares dizia respeito ao posicionamento das classes dirigentes, teóricos e profissionais da educação. Na tentativa de promover a instituição escolar como instituição importante no seio da sociedade, esses seguimentos hegemônicos tentavam, ao mesmo tempo, desqualificar e deslegitimar as ações das populações mais pobres em defesa da educação escolarizada. Agindo assim, poder público e classe dirigente promoviam uma desqualificação das próprias camadas populares, considerando-as como atrasadas e ignorantes e, por isso mesmo, incapazes de determinar e gerir seus próprios interesses. Tal representação, encontrando respaldo na sociedade, através da circulação desse ponto de vista em canais de comunicação, na 
ação jurídica e policial, justificava e autorizava a ação regeneradora da escola sobre os seguimentos empobrecidos da sociedade. Há uma tentativa relativamente fracassada de se escolarizar a população e uma desqualificação das ações dos mais pobres em defesa da educação escolarizada. Partindo daí, justificar-se-ia a representação pejorativa de que os pobres não se interessavam pela escolarização. Dentre esses, a quem se justificava a ação regeneradora da escola, estavam as crianças pobres, abandonadas, desvalidas, em risco moral e delinquentes.

\section{Referências}

CHARTIER, Roger. A História Cultural: Entre Práticas e Representações. Lisboa: DIFEL, 1990.

CUNHA, Marcus Vinicius da. A escola contra a família. In: Luciano Mendes de Faria Filho; Eliane M. Teixeira Lopes; Cynthia G. Veiga. (Org.). 500 Anos de Educação no Brasil. 1 ed. Belo Horizonte: Autêntica, 2000, p. 447-468.

DE CERTEAU, Michel. A invenção do cotidiano: artes de fazer. Petrópolis: Vozes, 1994.

DEMARTINI, Zeila. B. F.. Crianças como agentes do processo de alfabetização no final do século XIX e início do XX. In: Monarcha, Carlos. (Org.). Educação da infância brasileira. Campinas: Autores Associados, 2001, p. 121-156.

DE PÁDUA, João Antônio; MONTE-MÓR, Roberto L. M. Formação Histórica: três momentos da história de Belo Horizonte. Relatório final do projeto Belo Horizonte No Século XXI, modulo 1, BH: Cedeplar, Face/Ufmg, 2004. Disponível em:

$<$ http//www.cedeplar.ufmg.br/pesquisas/pbh/arquivos/Mod1.pdf $>$. Acesso em $09 / 11 / 2006$.

FARIA FILHO, Luciano. Dos pardieiros aos palácios: forma e cultura escolares em Belo Horizonte - 1906-1918. Tese (Doutorado em Educação). São Paulo: FEUSP, 1996.

FARIA FILHO, Luciano \& VIDAL, Diana. Disputa entre o governo da casa e o governo da escola. In: Revista Brasileira de Educação, no 14, Mai/Jun/Jul/Ago 2000.

FARIA, Maria Auxiliadora. Manifestações político-sociais da população belorizontina: 1930-1937. In: Seminário de Estudos Mineiros 6- a Revolução de 1930. Belo Horizonte: UFMG/Proed, 1987, p. 201.

FERREIRA, Sergio Guimarães \& VELOSO, Fernando A. Mobilidade Intergeracional de Educação no Brasil. Pesquisa e Planejamento Econômico, Rio de Janeiro, RJ, v. 33, n. 3, p. 481-513, 2003.

GONÇALVES, Irlen \& FARIA FILHO, Luciano Mendes. Processo de escolarização e obrigatoriedade escolar: o caso de Minas Gerais (1835-1911). In: A infância e sua 
educação: materiais, práticas e representações (Brasil e Portugal). Belo Horizonte: Autêntica, 2004.

NEVES, Delma Pessanha. A pobreza como legado. O trabalho infantil no meio rural da sociedade brasileira. Revista de História Regional, Ponta Grossa, v. 6, n. 2, p. 149-173, 2003.

NOGUEIRA, Maria Alice \& ALMEIDA, Ana. M. (Orgs.) A escolarização das elites. $2^{\mathrm{a}}$ ed. Petrópolis: Vozes, 2002.; da mesma autora et al:

NOGUEIRA, Maria Alice; ROMANELLI, Geraldo \& ZAGO, Nadir. (Orgs.). Família e escola: trajetórias de escolarização em camadas médias e populares. $2^{\mathrm{a}}$. Ed. Petrópolis: Vozes, 2000. $183 \mathrm{p}$.

ROCHA, Sonia. Trabalho precoce: realidade social e desafio de política pública. Nova Economia, Belo Horizonte, no 13 (2), jul./dez. de 2003, 61-80.

SOARES, Magda. Alfabetização e letramento. São Paulo: Contexto, 2003.

VAGO, Tarcisio Mauro. Cultura escolar, cultivo de corpos. Educação physica e gymnastica no ensino público primário de Belo Horizonte (1897-1920). Tese (Doutorado). São Paulo: FEUSP, 1999.

VEIGA, Cynthia Greive \& FARIA FILHO, Luciano Mendes. Belo Horizonte: a escola e os processos educativos no movimento da cidade. In: Belo Horizonte: cem anos em cem. Varia História. Revista do Departamento de História da UFMG. Belo Horizonte, $n^{\text {o. }}$ 18, Novembro de 1997, p. 203-222.

VINCENT, Guy; LAHIRE, Bernard \& THIN, Daniel. Sobre a história e a teoria da forma escolar. Educação em Revista, jun. 2001, p. 7-48.

SILVA, Wesley. Por uma história sociocultural do abandono e da delinquência de menores em Belo Horizonte 1921-1941. Tese (Doutorado em Educação). São Paulo: Faculdade de Educação/ USP, 2007 (344 p.). 